\title{
La Iglesia como agente de ô secularización. Municipalidades y Concordato en El Salvador, 1842-1862
}

\author{
Julián González Torres \\ Universidad Centroamericana \\ "José Simeón Cañas", UCA
}

Resumen: En este trabajo se analiza el rol de la Iglesia católica salvadoreña como agente de secularización. A partir del análisis de las relaciones de colaboración, tensión y conflicto entre la Diócesis de San Salvador y las municipalidades del Estado, y a partir del análisis del concordato firmado entre el Estado salvadoreño y la Santa Sede (1862). La investigación revela que en el proceso de secularización la Iglesia se desempeñó como agente y como producto de dicho proceso.

Palabras claves: Iglesia católica, Obispado, Santa Sede, Estado salvadoreño, municipalidades, secularización.

Abstract: This paper analyzes the role of the Salvadoran Catholic Church as an agent of secularization. From the analysis of the relations of collaboration, tension and conflict between the Diocese of San Salvador and the municipalities of the state, and from the analysis of the Concordat signed between the Salvadoran State and the Holy See (1862). This research reveals that in the process of secularization the Catholic Church served as an agent and as a product of that process.

Keywords: Catholic Church, Bishopric, Holy See, Salvadoran State, municipalities, secularization. 


\section{Introducción}

Esta investigación sostiene que en el proceso histórico de secularización, en el siglo XIX, la Diócesis de San Salvador fue un actor importante. Cuando el Obispo Tomás Miguel Pineda y Saldaña trazaba límites en beneficio de la autonomía administrativa, económica y pastoral de la Iglesia marcaba fronteras entre el poder político y el religioso, entre el Estado y la Diócesis. Ese esfuerzo eclesial por diferenciar y separar la jurisdicción de ambos poderes era una forma de secularizar la sociedad salvadoreña.

Paradójicamente ganaban ambos, la Iglesia y el Estado. Nos enfocamos en dos acciones. En primer lugar, en las relaciones de tensión, colaboración y conflicto entre la Diócesis y las municipalidades. De manera especial, a partir de la tensión en torno a la administración y el uso de los fondos de fábrica. En segundo lugar, en la firma del concordato entre el Estado y la Santa Sede. Este acuerdo contribuyó al proceso secularizador porque diferenció y separó las funciones y las acciones de ambos poderes.

El interés por estudiar la Diócesis de San Salvador se vincula con el hecho de que la erección del obispado fue una de las principales demandas de las autoridades sansalvadoreñas desde el período colonial. La demanda cobró más fuerza en el contexto de la independencia. Las autoridades políticas de San Salvador creían que la independencia sería un logro a medias mientras las autoridades eclesiásticas de Guatemala y la Santa Sede no consintieran la erección de una diócesis en el territorio.

Esta forma de ver las cosas tenía sus raíces en la Colonia. El poder político y el religioso se articulaban en un solo fin: el bienestar de las almas durante la vida y después de la muerte. De forma que era inconcebible un Estado sin una jurisdicción episcopal en su territorio. Tener diócesis equivalía a ostentar una auténtica y plena soberanía política. $Y$ es que, en un sentido amplio, al final, en cada pueblo los vecinos y/o ciudadanos eran los mismos feligreses. Así que, aunque parezca una tomadura de pelo, mientras el Estado del Salvador no tuviera diócesis, tendría ciudadanos pero no feligresía. Esta, formal y eclesialmente, pertenecía al Arzobispado de Guatemala. Tener una feligresía propia era un asunto político de urgencia. Y se solventaría teniendo una diócesis en el territorio. Al poseerla, la máxima autoridad eclesiástica sería el obispo y sería el pastor de todos los curatos del territorio. Así, juntos, Estado y Diócesis, gobernarían a la población en lo civil y en lo espiritual. Por otro lado, para el Estado tener un obispado significaba control y poder sobre los curas y la feligresía del territorio. 
Este artículo ha sido elaborado a partir del informe del proyecto La Iglesia frente al Estado: poder y tensiones en El Salvador, 1842-1871, respaldado por el Departamento de Filosofía y financiado por el Fondo de Investigación de la Universidad Centroamericana José
Simeón Cañas, para el período de septiembre de 2018 a diciembre de 2019. Las fuentes primarias han sido consultadas en el Archivo Histórico del Arzobispado de San Salvador (AHASS) y en Colecciones Especiales de la Biblioteca "P. Florentino Idoate, S.J.".

\section{La secularización y sus agentes. Significado histórico y político}

Bajo el influjo de la crítica ilustrada a la religión, la laicidad de corte francés, el progreso políticoeconómico y la tolerancia religiosa en los Estados Unidos, las logias de la masonería y de pensamientos como el krausismo, las repúblicas del continente latinoamericano, desde México hasta Argentina, se embarcaron en un proceso de laicización y secularización, en el último tercio del siglo XIX. Se lograron reformas como la secularización de cementerios, la escuela laica, el matrimonio civil, la libertad de culto y el Estado aconfesional (González, 2012; Vásquez, 2012; Valdés, 2010; Blancarte, 2008; Lionetti, 2007; Rausch, 1993).

La Iglesia católica latinoamericana ha sido interpretada como una institución consolidada que en el último tercio del siglo XIX entró en un proceso de abierta confrontación con las autoridades estatales que imponían la laicización y la secularización a fuerza de reformas. De forma que al lograr la separación de la Iglesia y el Estado -a través de constituciones, leyes, decretos y reglamentos-, cada institución (la Iglesia y el Estado) avanzaría por caminos diferentes esa modernidad impuesta a fuerza de reformas estatales. Pero el concepto de una Iglesia consolidada no se sostiene. A decir verdad, la Iglesia estuvo en proceso de configuración institucional durante todo el siglo XIX. Por otro lado, tampoco se sostiene la imagen de una Iglesia sin una intervención activa y determinante en el proceso histórico de secularización (Di Stefano, 2011, 2004).

Según Di Stefano, es común traslapar, de forma inapropiada en la mayoría de casos, tres acepciones de Iglesia: (1) el sentido teológico como comunidad de fieles, ya sea como Iglesia universal o en referencia a una diócesis (un obispado) en particular; (2) el sentido que remite al clero o "estado eclesiástico", que tiene su anclaje en el Antiguo Régimen, donde el clero era una corporación más entre otras; (3) la acepción jurídicopolítica que conceptúa a la Iglesia 
como "una entidad equiparable al Estado, dotada de una estructura organizativa integrada y subordinada al poder papal de manera directa" (Di Stefano 2012, p. 221).

El principal error consiste en tomar el tercer sentido y trasladarlo de forma anacrónica a la época de la Colonia y de la primera mitad del XIX. A juicio del autor, al menos para el caso rioplatense $-\mathrm{y}$ considero que también para el caso de El Salvador y Centroamérica-, este tercer sentido de Iglesia apenas está en proceso de construcción en el transcurso del $X I X$. De forma que al mismo tiempo que se constituye como institución jurídico-política, frente al Estado, que está también en proceso de formación, la Iglesia actúa social, política y jurídicamente como un agente más del proceso secularizador (Di Stefano, 2011, p. 8). Como apunta el autor, "la Iglesia en cuanto entidad jurídico-política nace en relación dialéctica y especular con la construcción del Estado centralizado y [...] ese doble desarrollo constituye un aspecto fundamental del proceso de secularización" (Di Stefano, 2012, p. 210).

El "concepto espacio-estructural de secularización describe sólo cambios en la localización de la religión cristiana desde la sociedad medieval a las sociedades modernas" (Casanova, 2012, p. 21). El núcleo fuerte y la tesis central de la secularización remiten al surgimiento de un período de modernización en el que se da un "proceso de diferenciación funcional y emancipación de las esferas seculares -en primer lugar, el Estado, la economía y la ciencia- de la religión así como la diferenciación, concomitantemente especializada, de la religión dentro de su propia, nuevamente creada, esfera religiosa". Las subtesis de la secularización como declive o decaimiento y como privatización de lo religioso derivarían de aquélla tesis central (Casanova, 2012, p. 23). ${ }^{1}$

La Iglesia en América fue un agente importante en el proceso de diferenciación funcional y de separación de esferas. En dos sentidos: hacia afuera, frente al Estado y ante cualquier otro tipo de instituciones o corporaciones con capacidad de disputarle poder y control sobre la feligresía; hacia dentro, en el sentido de forjar su propio proceso de institucionalización, control e identidad en el corazón de una sociedad que otrora se conceptuaba como natural e indiscutiblemente cristiana católica. La secularización es "un proceso social" en el que participan la Iglesia y el Estado, pero las raíces socioculturales del proceso no se agotan en las relaciones de colaboración, conflicto y diferenciación entre ambas instituciones. La laicización, por otro lado, sería "un proceso legal" impuesto por el Estado (Poulat, 2012, p.131). 
En este trabajo reconocemos que en Centroamérica, durante el período de la República Federal (18241839), los liberales más radicales ensayaron reformas secularizantes, como el caso de Mariano Gálvez, Jefe de Estado de Guatemala entre 1831 y 1838 (Wortman, 2012, pp. 323-341; Gudmundson, 1995, pp. 100-110). Pero no compartimos el concepto de secularización de Gudmundson. Dicho concepto queda preso del enfoque reformista (el Estado contra la Iglesia) y entiende la secularización como un asunto meramente del Estado. Desde nuestra perspectiva, como ya se explicó, Estado e Iglesia son coagentes en el proceso histórico de secularización.

Para comprender el doble papel de agente y producto de la secularización es necesario poner en remojo, metodológicamente hablando, las distinciones binarias contemporáneas entre poder político/civil/ estatal y poder religioso/espiritual/ eclesial. Estas marcas binarias no explican el proceso de secularización, más bien son un producto de esta. Quien vivía en la sociedad de Antiguo Régimen podía comprender la distinción entre lo civil y lo espiritual, pero tal distinción no indicaba necesariamente una estricta separación entre ambos órdenes. Según Di Stefano, los poderes temporal y espiritual trabajaban por un mismo objetivo, que se atendía desde dos planos: "la cohesión de la comu- nidad por medio del gobierno y de la justicia -civil y eclesiástica- en el plano terrenal (para la generación presente) y la salvación de las almas en el plano sobrenatural/sacramental (en la perspectiva de la eternidad)" (Di Stefano, 2012, p. 202). Para lograr esa doble finalidad, "el poder temporal desempeña funciones que vistas desde nuestra visión actual son religiosas, así como el poder espiritual desempeña funciones que desde la misma óptica son políticas" (Di Stefano, 2012, p. 205).

La Iglesia se desempeñó como "otra rama del gobierno real, otro medio de control político sobre los colonos, vivía bajo las orientaciones del Consejo de Indias y estaba unida a Roma por lazos muy tenues" (Avendaño, 2018, p. 46). La ambigüedad o traslape de ambas partes en un complejo proceso de construcción republicana marcará las relaciones de colaboración y conflicto entre el Estado y la Iglesia. Parte del proceso consistirá en disputar y marcar ciertas líneas fronterizas a partir de las cuales la Iglesia forjará su relativa autonomía institucional frente al Estado y otros poderes, a través de la integración-estructuración del territorio como Iglesia nacional y mediante la subordinación a la Santa Sede. Un proceso que debe comprenderse desde el proceso mayor de romanización que llevó a cabo la Iglesia, a partir de la elección de Pío IX,quien presidió la Santa Sede desde 
1846 hasta 1878 (De Roux, 2014). En el siguiente apartado daremos una explicación breve de cómo San

Salvador se erigió en diócesis.

\section{Breve nota de cómo San Salvador llegó a ser Diócesis}

Por información del cura José Ignacio Ávila sabemos que en 1778 el Arzobispo Pedro Cortés y Larraz propuso al Rey Carlos III la erección de una diócesis en las vicarías provinciales de San Salvador (San Salvador, Santa Ana, San Vicente y San Miguel) (Malaina, 1944, p. 52; Vilanova, 1911, pp. 27-37). Pero la recomendación no se tradujo en hechos. Años después, cuando la Alcaldía Mayor de San Salvador fue elevada a Intendencia (1785) se le otorgó al intendente el ejercicio del vicepatronato, que suponía el derecho a tener sede episcopal, pero el arzobispo de Guatemala se opuso a que hubiese obispado en San Salvador (Avendaño, 2011, p. 33) ${ }^{2}$. En el contexto de la crisis monárquica, por la invasión napoleónica a la península ibérica, y de la convocatoria a elección de diputados para las Cortes Generales y Extraordinarias (Las Cortes de Cádiz), el Ayuntamiento de San Salvador eligió al cura José Ignacio Ávila, vecino de San Miguel, como su representante. El 21 de marzo de 1812, Ávila presentó ante las Cortes la petición del ayuntamiento de tener su propio obispado, quedando este separado de Guatemala (entiéndase la ciudad capital y las provincias de Sonsonate, Verapaz, Quezaltenango y Sololá). Cuatro razones respaldaban la petición: (1) la numerosa población de la Intendencia de San Salvador: se estimaban 180,000 almas, distribuidas en 126 pueblos; (2) la extensión del territorio: la Intendencia se componía de 15 partidos o subdelegaciones, distribuidos en San Salvador (cabeza de la Intendencia), Santa Ana, San Vicente y San Miguel; (3) la distancia entre la metrópoli (Guatemala) y San Salvador, (4) el dinero recolectado por el pago del diezmo (Malaina, 1944, pp. 51-52; Herrera, 2018, pp. 74-78).

Para tener una idea de lo que San Salvador tributaba, valga mencionar que en 1817 envió a la capital 41,512 pesos seis reales en concepto de diezmo, un monto que solo por poco era superado por el resto de los territorios del Reino de Guatemala (Herrera, 2005, p. 157). Ávila declaró que "los diezmos de San Salvador son más que suficientes para dotar la mitra y demás establecimientos anejos; pues que, regulados bajamente, producen cada año 40,000 pesos fuertes" (Malaina, 1944, p. 52). En junio de aquel mismo año, la Corona emitió una Real Cédula en la que ordenaba al Capitán General, José de Bustamante y Guerra, que procediera a la elaboración del expediente respectivo para la erección de la diócesis (Vilanova, 1911, p. 49). Al no ver resultados, 
las autoridades de San Salvador escribieron al rey y, al no ver resultados una vez más, escribieron a la Diputación Provincial de Guatemala. Pero no hubo respuesta efectiva para San Salvador hasta diciembre de 1818, cuando una Real Cédula ordenó la división de los curatos del Arzobispado de Guatemala y la erección de una nueva diócesis, según las necesidades espirituales de la población. El Capitán General Carlos Urrutia inició el trámite y este fue continuado por Gabino Gaínza (Ayala, 2011, pp. 142-148). Cuando parecía que San Salvador por fin se separaría del Arzobispado de Guatemala y tendría su propia diócesis, las autoridades metropolitanas declararon la independencia de la Corona española. El trámite eclesiástico quedó truncado y nuevas tensiones y disputas surgieron entre la metrópoli (Guatemala) y las autoridades de San Salvador.

El 30 de marzo de 1822, la Junta Provisional Gubernativa de San Salvador erigió la sede episcopal y nombró a José Matías Delgado como primer obispo. Los asambleístas respaldaron el decreto en los años que llevaban solicitando el obispado; los diferentes ocursos enviados al gobierno de la Corona; los trámites más recientes, antes de la firma de la independencia; el crecimiento de la población y la falta de las visitas pastorales en los curatos de San Salvador; la capacidad económica del territorio para sostener al obispado. Apegado al guión del patronato regio, el gobierno debía hacer la "suplicatoria correspondiente a su Santidad, [...] a efecto de que se digne confirmar este Acuerdo y mandar expedir en consecuencia las Bulas de estilo" (Malaina, 1944, p. 54)3. Como Guatemala y San Salvador estaban enfrascados en una guerra por la oposición de este a la anexión de Centroamérica al Imperio Mexicano encabezado por Agustín de Iturbide, el decreto no pasó a más, de momento (Vázquez, 2009). En noviembre de 1822, el Congreso del Salvador confirmó la erección del obispado y el nombramiento de Delgado.

El dominio imperial de Agustín de Iturbide terminó en 1823. El antiguo Reino de Guatemala inició su experiencia republicana y federal. Pero la unidad política de las antiguas provincias sería algo imposible (Pinto, 1986, pp. 174-208). En contra de la autoridad del Congreso Federal, en 1824 las autoridades de San Salvador ratificaron las acciones de 1822. Erigieron la diócesis y nombraron obispo a José Matías Delgado. La reacción de Guatemala no tardó en llegar. El Arzobispo Fray Ramón Casaus y Torres denunció ante Su Santidad León XII la falta cometida por el Estado salvadoreño y el cura Delgado. La Santa Sede acusó de "lobo" e "intruso" a Delgado y ordenó a Casaus y Torres que lo amonestara. El arzobispo instó a Delgado a que desistiera de sus aspiraciones ecle- 
siásticas y le advirtió que aún estaba a tiempo de "salvar [...] su alma, y precaver a los fieles de los progresos del cisma, en que Usted mal dirigido se está empeñando" (Ayala, 2011, pp. 174,179). La acción del Estado salvadoreño provocó la división del clero y la expulsión de unos cuarenta eclesiásticos, quienes no reconocieron el nombramiento de Delgado (Malaina, 1944, p. 15). Por otro lado, entre 1826 y 1829 aconteció la primera guerra federal, que dejó al frente de la República Centroamericana al General Francisco Morazán. Una de las consecuencias de esta guerra fue el destierro, en julio de 1829, con destino a La Habana, del Arzobispo Casaus y Torres.

Entre 1831 y 1842 , los curatos del Salvador estuvieron bajo la dirección pastoral de un vicario, quien era nombrado por las autoridades eclesiásticas de Guatemala. Pero las tensiones y disputas continuaron entre el Estado del Salvador y su clero, las autoridades eclesiásticas de Guatemala,y las autoridades federales. En otro estudio se analiza esta problemática. El fin de la Federación Centroamericana contribuyó a la erección definitiva de la diócesis. El 28 de septiembre de 1842, la Santa Sede erigió la Diócesis en San Salvador y en enero de 1843 nombró obispo a Jorge de Viteri y Ungo.

Viteri y Ungo ostentó el título de 1843 a 1849, pero por la convulsión política desatada en julio de 1846 , en la que el obispo estuvo directamente involucrado, éste se autoexilió en ese mismo mes y año (Delgado, 2011, pp. 406-445; Bolaños, 2001, pp. 295-359). Teniendo en cuenta que tras su preconización, cuando estaba de visita en la Santa Sede como Enviado Extraordinario de los Estados centroamericanos ${ }^{4}$, regresó a El Salvador en septiembre de 1843 , en realidad en la Diócesis no residió ni tres años. El escaso tiempo del que dispuso no le permitió cumplir de forma adecuada con uno de los mandatos prioritarios del Concilio de Trento: las visitas pastorales (Laboa et al., 2005, pp. 604, 607). Hizo visitas entre 1844 y 1846 , pero las fuentes indican que fueron hechas a la carrera, sin la diligencia necesaria.

Tras el autoexilio de Viteri y Ungo, en julio de 1848 Tomás Miguel Pineda y Saldaña fue designado por la Sagrada Congregación Consistorial para que administrara la diócesis. Fue consagrado obispo en febrero de 1849 y en marzo de 1853 fue notificado de forma oficial como nuevo obispo de San Salvador (Delgado, 2011, p. 454).

Pineda y Saldaña nació en el curato de San Pedro Masahuat en 1791. Realizó estudios en Guatemala. En septiembre de 1819 fue ordenado sacerdote. En 1820 asumió el curato de Izalco. Según sus biógrafos, fue un firme opositor al cisma provocado por José Matías Delgado. En 1844 fue nombrado provisor y vicario 
general de la diócesis. En febrero de 1850 , comenzó las visitas pastorales. Inició con la parroquia de San Pedro Metapán. Su trabajo pastoral a través de las visitas fue clave para el proceso de institucionalización de la Diócesis de San Salvador como Iglesia nacional. Tras una desavenencia con el Presidente Gerardo Barrios, en noviembre de 1861 abandonó el país rumbo a Guatemala. Quizá angustiado y temeroso de que se dieran hechos similares a cuando el Obispo Viteri y Ungo dejó el obispado o, peor aún, a cuando el General Francisco Morazán desterró al Arzobispo Casaus y Torres. No regresó a El Salvador sino hasta 1863 , tras el derrocamiento de Gerardo Barrios. Murió el 6 de agosto de 1875. Le sucedió como tercer Obispo José Luis Cárcamo y Rodríguez (Delgado, 2011, pp. 453-454; López, 1999, pp. 75-98). En el siguiente apartado analizaremos el papel de la Diócesis en el proceso de secularización.

\section{La tensión secularizadora entre la Diócesis y las municipalidades}

En el tiempo de la Federación, en 1832, el Estado salvadoreño aprobó el Reglamento de Jefes Políticos, Municipalidades y Alcaldes. Buena parte de las funciones aprobadas por el reformismo liberal gaditano pervivieron (Art. 321. Constitución política de la Monarquía española). Entre las principales responsabilidades de la municipalidad estaban: cuidar el orden, la tranquilidad y la seguridad de las personas; velar por la salubridad para preservar la salud pública, mediante la limpieza en calles, plazas, mercados, cárceles y hospitales; cuidar de la higiene en la venta de alimentos; elaborar el censo y la estadística de la población; construir y componer caminos, calzadas, puentes y cárceles; evitar los incendios en montes y campos; elaborar el registro de los ciudadanos según la división por cantones de cada pueblo; construir el padrón según edad, sexo y ocupación; nombrar alcaldes auxiliares en aquellos territorios sin municipalidad, así como en los barrios de los pueblos con gobierno municipal; velar por la exactitud en el peso $y$ en medidas de cualquier clase; fomentar la agricultura, las artes y la ciencias; repartir las contribuciones designadas a los pueblos; velar por que la población tenga ejidos y tierras comunales; velar por que los niños y jóvenes asistan a las escuelas de primeras letras; nombrar un mayordomo colector de los fondos de propios y arbitrios; asistir con la decencia debida a las fiestas religiosas y cívicas, y presidiría el alcalde primero cuando no estuviera el gobernador; velar por la construcción de cementerios, cuidando la seguridad y decencia en dichos establecimientos; recaudar, administrar e invertir los fondos de propios y arb 
trios. (Menéndez, 1855, Libro Cuarto, Título 2, pp. 190-192).

Las investigaciones que han estudiado el poder y el rol de las municipalidades han analizado el trabajo de estas a partir del proceso de construcción del Estado. De los trabajos publicados se desprenden cuatro conclusiones: después de la independencia, durante la Federación y en los años posteriores a su declive, las municipalidades fueron el rostro visible de los gobiernos en los pueblos; a partir de la década de 1860 se dio un proceso de centralización estatalgubernamental que hizo decrecer el poder y la autonomía de las municipalidades; en el contexto local las municipalidades eran un ejemplo más de la precaria e injusta base fiscal que las oligarquías cimentaron en el XIX; hubo diferencias fiscales marcadas entre aquellas municipalidades urbanas y más antiguas (San Salvador, Santa Ana, San Vicente, San Miguel, por ejemplo), ricas en rentas, y aquellas olvidadas en algún lugar del Estado, que apenas sobrevivían con los gastos ordinarios (Pérez, 2012, 2018; López, 2007, 2018; Acosta, 2014; Acosta y Flores, 2011).

La investigación en torno a la construcción del Estado es incompleta si no se estudia el poder y las funciones de otro actor clave, un tipo de gobierno invisible en apariencia pero esencial en el tejido de la vida comunitaria y cotidiana: el cura y la parroquia. Las relaciones de poder acontecieron no solo entre las instituciones y los actores del gobierno ejecutivo (presidentes, gobernadores, la hacienda nacional, etc.) y las municipalidades (alcaldes, regidores, secretarios municipales, etc.), sino también entre estas y las parroquias, entre los alcaldes y los curas, entre las municipalidades y el obispo. La composición territorial y la articulación social del curato, la administración de los sacramentos y la función sociopolítica encarnada por el cura párroco habían moldeado la vida de los pueblos desde la Colonia. La evidencia sugiere que la importancia de los curatos no decreció a pesar de la revolución del liberalismo gaditano y de la separación del Reino de Guatemala de la Monarquía española (Avendaño, 2018, pp. 90-93; Herrera, 2013, pp. 139-146, 2004; Cardenal, 2001, pp. 197-237).

Hacia 1855, la Diócesis de San Salvador se componía de 53 parroquias y contaba con "72 sacerdotes con responsabilidad pastoral en sus respectivas parroquias, y 22 que por razones diversas no tenían beneficio ni parroquia" (Delgado, 2011, p. 452). La población se estimaba en 394,000 habitantes (Barón, 2002,p.411). En un cálculo elemental, cada párroco tenía bajo su responsabilidad espiritual un aproximado de 5,472 almas. Era un número inmanejable para el trabajo pastoral, sobre todo en un territorio donde predominó un asentamiento poblacional dispersado y donde el 
grueso de la población vivía en el campo (Acosta, 2016, p. 31).

Aquí nos centraremos en las relaciones de colaboración, tensión o conflicto entre el obispo de San Salvador y las autoridades municipales. A fin de constatar el proceso de secularización fraguado por estos actores, según la definición planteada en el primer apartado. En concreto, estudiaremos las tensiones y disputas respecto a la administración y el destino de los fondos de fábrica. Se explicará de qué forma la Diócesis de San Salvador contribuyó a ese proceso decimonónico de separación y distinción de esferas. El corpus de fuentes primarias serán los autos de las visitas pastorales realizadas por el Obispo Pineda y Saldaña.

Los fondos de fábrica se crearon originalmente para la construcción de iglesias. Con el tiempo se sumaron las reconstrucciones, las reparaciones y los gastos en general en la edificación sacra, así como en adornos, alhajas, ornamentos y en los elementos necesarios para los rituales del culto católico (Diccionario de Derecho Canónico, p. 9). Un mayordomo debía administrar estas rentas.

Estos fondos eran escasos por tres razones: por lo general era un aporte que pagaban los ladinos y no siempre lo pagaban, los indígenas "pagaban" con servicio (reconstruyendo, reparando u ornamentando los templos); no se llevaba una administración diligente y transparente, lo que daba lugar a abusos, como cuando se hacía un pago excesivo de honorarios al mayordomo; las municipalidades solían administrar o utilizar dichos fondos, con lo que se desvirtuaba el objeto inicial para el que fueron creados.

En diciembre de 1853, el párroco de San Pedro Masahuat, Buenaventura Guerrero, admitió que no tenía participación en el manejo de los fondos, excepto en algunos gastos. "No hay mayordomia de este ramo [fábrica] sino [...] este pueblo, el encargo de la cual es hecho por la municipalidad sin ninguna intervencion del Párroco; sin embargo en algunos gastos que han parecido indispensables la ha procurado tener el que habla [Guerrero]". (Libro de visitas pastorales, $1850-1854$, f. 215-271 [216]). Lejos de reprender al párroco o de hacer una advertencia a la municipalidad, el obispo autorizó que esta y el párroco presentaran la terna de nombres para elegir al mayordomo. Una ley de enero de 1852 estableció que "los Mayordomos de Fábrica serán nombrados por el Gobierno Eclesiástico, á propuesta en terna de las Municipalidades respectivas, y con asistencia y voto del Cura del lugar", el nombramiento duraría dos años, podrían ser reelectos y rendirían cuentas a la Curia cada fin de año (Menéndez, 1855, Libro Séptimo, Título 4, p. 78) $)^{5}$. La actitud del prelado no siempre fue la misma. 
De San Pedro Masahuat se desplazó a las parroquias de Santiago Nonualco y San Pedro Ostuma. En la primera, en el pueblo de San Juan Nonualco, advirtió a la municipalidad en los siguientes términos:

El mayordomo de fabrica de San Juan, presentó sus cuentas de seis años, recibidas sin razon alguna de sus antecesores; y como se hayan en absoluto desarreglo, se previene al espresado mayordomo las presente al parroco, sin dar al Cuerpo Municipal intervencion ninguna para revisarlas, y menos aun para disponer de sus fondos. (Libro de visitas pastorales, 1850-1854, f. 184)

Mientras en este asunto el prelado exigió ningún tipo de intervención por parte de la municipalidad, el mismo informe de la visita incluyó el "Ynbentario de las alhajas de la Yglesia [de San Juan Nonualco] que por acuerdo municipal [...] se ha mandado formar" (Libro de visitas pastorales, 1850-1854, f. 192). Un mismo auto de visita revela tensiones y trabajo en conjunto entre el poder civil y el religioso.

Al año siguiente, en 1854, en la parroquia de San Juan Bautista Chinamenca la palabra del obispo volvió a un tono cordial. Revisadas las cuentas del mayordomo José María Lemus, comprendidas entre 1839 y 1853, resultó de cargo (ingresos) la cantidad de 502 pesos seis reales, de data (gastos) el monto de 183 pesos un real, de dinero en efectivo 319 pesos cinco reales y un monto de deuda que sumaba 432 pesos cinco y medio reales. Ante las impostergables reparaciones que el templo parroquial demandaba, el prelado ordenó la creación de una junta directiva para dicho objetivo. Quedaría compuesta por el párroco (Nicolás Silva), el alcalde (Juan Tomás Romero, aun cuando dejare de serlo), el Licenciado D. Francisco Zamora, un regidor del cuerpo municipal y por el mayordomo de fábrica. En primer lugar, se emplearían los 432 pesos cinco y medio reales en concepto de deuda para las obras de construcción, por lo que sería necesaria la intervención de las autoridades civiles para que los deudores saldaran cuentas. En segundo lugar, se tomarían 219 pesos cinco reales del dinero en efectivo para el mismo fin,"quedando el resto de cien p.[eso] s para las demás necesidades de la misma Yglecia”. Además de mostrar confianza en el trabajo de la municipalidad, diferente al pueblo de San Juan Nonualco, el auto revela dos elementos importantes: (a) la reparación del templo dependería, en buena parte, de la diligencia de las autoridades civiles en el cobro de las deudas; (b) solo se presupuestaría el jornal de carpinteros y albañiles, "pues que esperamos, que sin él [sin jornal], los hombres y mujeres del pueblo ayudarán á la obra" (Libro de visitas pastorales, 1850-1854, f. 331-332). Esto seguramente se debía a que los indígenas no contribuían 
con dinero para los fondos de fábrica, aunque el texto no especificó si solo indígenas trabajarían en la construcción del templo.

En la misma parroquia de San Juan Bautista, pero en el pueblo de Lolotique, la postura del prelado fue diferente. El mayordomo de fábrica presentó las cuentas comprendidas entre 1846 y 1853. Los registros revelaron 275 pesos seis reales de cargo, 131 pesos seis y medio reales de data, quedando en existencia 143 pesos siete y medio reales. El párroco cuidaría que este dinero "se invierta en techar de nuevo la Yglesia". Los alcaldes debían reparar una acción que la municipalidad había ejecutado sin el permiso debido: "procurando los alcaldes de d[ic]ho pueblo, que el maestro carpintero Sr. Vicente Velis cumpla su contrato ó pague su fiador la suma de ciento veinte $\$$. [pesos] que del fondo de fabrica, q[u]e no debiendo darle, le dio la municipalidad sin nuestro permiso" (Libro de visitas pastorales, 1850-1854, f. 332-333). El texto no especifica si este dinero era parte de los 143 pesos siete y medio reales en efectivo o si estaba registrado como anticipo o como deuda, al margen de las cuentas revisadas. No obstante, es evidente el conflicto entre el poder religioso y el poder civil en la administración y en el uso de estos fondos.

En la parroquia de San Alejo, en el pueblo de La Unión, los números no eran muy alentadores como en Chinameca y Lolotique. Las cuentas de seis años (de 1848 a 1853) apenas registraban 35 pesos cuatro reales de cargo, 68 pesos siete y medio reales de data, alcanzando al mayordomo el monto de 33 pesos tres y medio reales (entiéndase un déficit que debía cubrirse). El nuevo mayordomo, Narciso Sosa, reintegraría la cantidad sobregirada al mayordomo saliente mediante el cobro de las deudas de fábrica, que ascendían a un total de 64 pesos cuatro reales. El resto de la deuda, "treinta y un pesos medio r.[ea]l se emplearan en la reconstruccion del templo de la Union". El auto de visita consignó un reclamo que salpicaba al gobernador departamental. El prelado exigió que se invirtiera en la reconstrucción de la iglesia la cantidad de 100 pesos que "del ramo de fabrica se tomaron indebidamente por el Gob[ernado] r. Depart[amenta].l para emplearlos en la construccion del cabildo" en abril de 1849. El párroco capellán debía reclamar el reintegro de dicho dinero. (Libro de visitas pastorales, 1850-1854, f. 456). Este es un claro ejemplo de que no siempre los fondos de fábrica se utilizaban para los fines religiosos que, por su génesis, le correspondían.

En la parroquia de Santiago Apastepeque, en el pueblo de San Sebastián, el prelado advirtió a la municipalidad. El libro de cuentas registraba solo el año de 1853, su cargo era de 286 pesos dos y medio 
reales, la data ascendía a 126 pesos un real, la existencia en dinero era de 41 pesos cuatro y medio reales y reportaba un total de deuda por 107 pesos siete reales. Del dinero en efectivo el prelado ordenó que "se invirtiesen 30 \$. [pesos] en candeleros, que no los hay en la Yglesia y los 11. \$ [pesos] con 4. y $1 / 2 \quad r$ r.[eale]s, quedasen para los gastos ordinarios de ella”. Exhortó a las autoridades civiles a interponer sus buenos oficios para el cobro de la deuda, dinero que se destinaría también para las necesidades del templo. Concluyó:

el cuerpo municipal, no está por ninguna ley vijente, autorizado para disponer de los fondos de fabrica; pues que solo es privativo de la autoridad ec[lesiásti]ca.; y si el mayordomo del ramo, no obstante esta prevencion, hiciese algun gasto de or[de] n. municipal, no se le abonará por legitima data (Libro de visitas pastorales, $1850-1854$, f. 377) ${ }^{7}$

Según veíamos al inicio de este apartado, las municipalidades debían procurar la salubridad del pueblo para asegurar la salud de la gente y debían garantizar la construcción de cementerios, así como velar por su seguridad y decencia. La visita de la parroquia de San Pedro Metapán, en 1850, revela que en algunos casos las municipalidades no solo no cumplían con su deber, sino que este era asumido por las parroquias. Según las cuentas de fábrica, la parroquia tenía un sobrante de 259 pesos cuatro reales. El prelado autorizó al párroco tomar 50 pesos para "aumentar el recinto del cementerio, y evitar asi que la putrefaccion de los cadaveres hacinados unos sobre otros aumente la enfermedad que se padece en esta poblacion" (Libro de visitas pastorales, 18501854 , f. 9). Por la solvencia de los fondos de fábrica es probable que la municipalidad fuese solvente en sus cuentas. No obstante, tocaba a la parroquia mejorar el camposanto a fin de prevenir las enfermedades.

Un escenario parecido encontró el obispo en la parroquia de Santa Bárbara, en Sensuntepeque, en 1854. El mayordomo Juan Ayala rindió cuentas del período comprendido entre julio de 1846 y febrero de de 1854. Su cargo ascendía a 577 pesos cuatro reales, su data a 286 pesos, su deuda era de 258 pesos tres y medio reales y los fondos disponibles sumaban 33 pesos. El obispo previno al párroco Juan Francisco Fuentes y al mayordomo para que el disponible lo destinaran "para las necesidades de la Yglesia". Exhortó a las autoridades civiles al cobro de la deuda (258 pesos tres y medio reales) para que "antes de que comiensen las aguas [lluvias de invierno], se levanten las paredes del campo santo". Ordenó que se colocara en el cementerio una "puerta segura con su llave, invirtiendo en este objeto otra cantidad que se nos ha $\mathrm{d}[\mathrm{ic}]$ ho. esta reunida con el mismo 
fin". Procediendo de esta forma "se evitará que los cadaberes sean exhumados por los perros y devorados por las aves de rapiña como sucede segun se nos ha asegurado". (Libro de visitas pastorales, 1850-1854, f. 412-413).

Menos afortunada era la situación en la parroquia de San Juan Cojutepeque, en el año de 1860. El visitador, que en dicha ocasión era el Vicario Provincial Andrés Aguilar, señaló que la falta de cementerio impedía que los fallecidos en los valles y en los poblados aledaños fueran enterrados en la ciudad; incluso muchos del poblado central eran "enterrados furtivam[en].te por que el lugar destinado á los enterramientos se halla en campo abierto". Afirmaba que la parroquia hacía acopio de materiales para la construcción del cementerio. Quizá por este motivo informó sobre los fondos de fábrica con estas palabras: "carece absolutamente de fondos, y no podrá tenerlos hasta que se halla construido el campo santo" (Libro de visitas pastorales, T. 2, 1857-1867, f. 95, 102) ${ }^{8}$. El incumplimiento de la municipalidad tenía sin cementerio al pueblo, de forma que ponía en riesgo la salud pública. Además, contribuía a preservar las precariedades y carencias propias del templo y del culto; buena parte de los esfuerzos económicos de la gente lo consumía el interés por construir el cementerio, según expresa el visitador.
Como ha quedado en evidencia en los casos de San Pedro Masahuat y de San Juan Bautista Chinameca, en algunos pueblos las relaciones entre la municipalidad y la parroquia eran de mayor entendimiento, incluso de mucha complicidad. En 1857 le llegó el turno a la parroquia de San Nicolás, en Tonacatepeque. El mayordomo expuso las cuentas comprendidas entre 1851 y 1857 . En ese tiempo la mayordomía había recaudado la asombrosa cantidad de 2,520 pesos siete y un cuartillo de reales, de los que se habían invertido en la iglesia 1,936 pesos cuatro reales, reportando en efectivo un total de 585 pesos dos reales. $Y$ puesto que "los robos se han hecho tan frecuentes que ya no respetan ni los templos del Señor", el dinero existente y lo que se continuara ingresando debía guardarse

en un pequeño cofre con dos llaves distintas, de las que una ecsistirá en poder del P[adr]e. cura, y la otra en el del tesorero Sr. Franc. [isc]o Jimenez, y dicho cofrecito se colocará dentro de una caja grande que tendrá tres llaves distintas de las cuales, una, conservará el padre cura, otra el alcalde 1.0 y la otra el espresado mayordomo tesorero, en cuya casa permaneceran las cajas dichas; y ya sea p.[ar]a introducir ó estraer de ellas alguna cantidad, concurriran las tres personas referidas, las que llevaran sus libros en el cual sentaran la partida de las cantidades que se introdusca, ó bien se estraiga; 
no pudiendo gastarse una cantidad mas de cien pesos, sin consultarnos; manifestandonos la necesidad y objeto en que debe emplearse (Libro de visitas pastorales, T. 2, 1857-1867, f. 58-59).

Ante tan extraordinaria cantidad de fondos recaudados, y los aún disponibles, no extrañan las medidas tomadas por el obispo; a su vez, el alcalde debía estar bien recomendado por el párroco,Joaquín Mendoza, para ser incluido en la terna que custodiaría el dinero. $Y$ es que en algunos casos el mismo alcalde fue elegido mayordomo, como sucedió en la parroquia de Apaneca, en el pueblo de Juayúa, en marzo de 1861. El pueblo carecía de mayordomo de fábrica y "no debiendo faltar ésta [mayordomía] en ninguna poblacion hemos nombrado mayordomo al señor Apolinario actualmente alcalde" (Libro de visitas pastorales, T. 2, 1857-1867, f. 165-166). La cotidianidad del pueblo enlazaba profundamente el trabajo civil del alcalde y la municipalidad con el ministerio pastoral del cura y la parroquia. Es probable que el tono cordial o de disputa que utilizaba el obispo respondiera, en buena medida, a la cordialidad o a las diferencias (a veces quizá irreconciliables) entre la municipalidad y la parroquia, entre los alcaldes y los párrocos.

Otros ingresos que marcaron la disputa entre la Diócesis y las municipalidades fueron los fondos de cofradías y hermandades. El obispo insistía en que los fondos de estas asociaciones debían utilizarse en fines piadosos, lo que significaba tres cosas. En primer lugar, respondían a una práctica devocional generalizada, herencia del Antiguo Régimen, y, de manera específica, a las celebraciones religiosas por la advocación de la Virgen María, o santa patrona, o por el santo patrón del pueblo. En segundo lugar, eran usados con fines benéficos, para socorrer al prójimo en la enfermedad o en la hora de la muerte, por ejemplo, y que tuviera un funeral digno; al mismo tiempo, pagaban misas por las almas del Santo Purgatorio. En tercer lugar, contribuían al mantenimiento del templo y al sostenimiento del culto religioso regular y tradicional, más allá de las festividades en honor al santo patrón o a la santa patrona. Contribuían con ornamentos, vasos sagrados, hostias, vino, cera, entre otros. En una línea más secular, hay que decir también que las cofradías y hermandades eran fuente de crédito para la feligresía (Guerrero, 2016; del Valle, 2014; Castellón, 2014; Tanck de Estrada, 2004; Di Stefano, 2002; Lavrin, 1998). El obispo reclamaba porque buena parte de aquellos fondos se gastaban en música, baile, aguardiente, comida y pólvora durante las fiestas de los pueblos.

Más allá de aquellos usos no piadosos, el caso registrado en la parroquia de Santa Catalina Apopa, en 1857, en el pueblo de Guazapa, 
ilustra que el prelado podía recurrir a un lenguaje más sutil pero igualmente claro en su intención: definir las fronteras entre lo civil y lo eclesial. Además de otras hermandades, existía en el pueblo la del Santísimo Sacramento, cuya mayordomía estaba a cargo de la señora Evarista Mayorga, quien declaró "haber entregado en cinco años á la misma corporación [municipal] 325. \$. [pesos] restandole aun que cobrar 110. \$. [pesos]". Se inquirió a la municipalidad en torno al destino del dinero y esta "informó verbalmente, que de ellos se gasta mas de 60 . \$. [pesos] anualmente en las funciones, y que el resto se reparte al redito legal". Por lo que el obispo expresó:

[...] no pudiendo reglamentarse á la vez esta hermandad, ni mudarse desde luego la espresada mayordomo [Evarista Mayorga], sin peligro de perderse algunas cantidades; acordamos: que el padre cura, pasada la procsima funcion de Corpus, arregle esta hermandad, haciendo con palabras suaves y persuasivas al cuerpo municipal la advertencia de que si bien es muy piadoso y laudable que dichas corporaciones se empeñen en el aumento del culto divino, no es de su resorte el nombrar mayordomos, ni disponer de las limosnas, invirtiendolas en otro objeto distinto de aquel para que las han dado los fieles [...] (Libro de visitas pastorales, T. 2, 1857-1867, f. 85).
Con estas acciones la Diócesis de San Salvador estaba fraguando un proceso de diferenciación administrativa entre lo civil y lo eclesial.

En la parroquia de Santiago Texacuangos, en diciembre de 1853 , al cierre de la visita se le recuerda al párroco que es parte de su deber pastoral y moral enseñar a los niños la doctrina cristiana, así como visitar las escuelas para cerciorarse de que los preceptores enseñan la doctrina y de que utilizan "libros piadosos é instructivos que no contengan ideas irreligiosas e impías". En el mismo informe, páginas atrás, en vista de que las veinte hermandades de Santiago Texacuangos carecían de fondos y de que sus cofrades celebraban las funciones religiosas "de su industria y trabajo personal", el obispo derogó "lo prevenido en el auto de la visita anterior, que imponía á cada una de dichas hermandades, la contribucion de ocho reales anuales para dotar al maestro de escuela; que sobre no ser justo tomar de los fondos piadosos para este objeto, las leyes han destinado para él, el producido del tajo" (Libro de visitas pastorales, 1850-1854, f. 226-229) $)^{9}$. A su criterio, era responsabilidad de la Diócesis la instrucción intelectual y moral de los niños y niñas, pero el pago de maestros y el sostenimiento de las escuelas corrían por cuenta del Estado, a través de las municipalidades. Cooperación y diferenciación. Un proceso de secularización en marcha. 
Cuando las relaciones aumentaban de tensión se pasaba a la amenaza directa. En la parroquia de San Pedro Perulapán, en 1854, la corporación municipal había intentado vender el terreno donde estaba la casa parroquial y al no conseguir su objetivo, había procedido al cobro de alquiler al cura Irineo Antonio Recinos. El obispo determinó "para intelig[enci]a. del cuerpo municipal" que "en el caso de insistir en su injusta resolucion, trasladaremos la residencia del parroco á cualquiera de los otros dos pueblos anexos" (Libro de visitas pastorales, T. 2, 1857-1867, f. 285). Probablemente se refería a los pueblos San Bartolomé Perulapía y San Martín, que eran los anexos de la parroquia de San Pedro Perulapán. La amenaza no era un asunto menor, pues un pueblo que contaba con corporación municipal y con parroquia estaba mejor posicionado en términos de status y de poder $y$, por lo mismo, estaba por encima de los pueblos anexos. En el mismo informe, pero acerca del pueblo de San Bartolomé Perulapía, la confianza hacia el alcalde municipal quedó en evidencia. El mayordomo de fábrica presentó las cuentas de los años 1853 y 1854. El obispo concluyó:

como segun estamos informados hay campo santo amurallado de paredes y sus puertas con llave, los ochenta \$ [pesos] que tiene de existencia los dejamos en deposito del Sr. Alcalde 1.0 const[ituciona].l
Sr. Bernardino Marcial, para que tan luego como reuna la cantidad que desea y recauda en el pueblo, se compren los ornamentos que necesita la Yglesia de d[ic]ho. pueblo (...) (Libro de visitas pastorales, T. 2, 1857-1867, f. 283).

Durante la Colonia y en el XIX (o en buena parte de este), el trabajo de construir, reconstruir y reparar los templos estuvo bajo la dirección de las autoridades civiles (ayuntamientos, cabildos, ayuntamientos constitucionales y municipalidades, según sus diferentes denominaciones) (López, 2018: 195-197; Herrera, 2003: 114). A mitad del XIX, los gobernadores departamentales incluían en sus informes las construcciones, reedificaciones, reparaciones y mejoras de iglesias (portada, techo, paredes), sacristías, campanarios, capillas, conventos y cementerios. Es probable que la mayor parte del dinero procediera de los fondos de fábrica y de los fondos y bienes de cofradías y hermandades. Un decreto de marzo de 1844 precisó que la "administracion de los capitales y cualesquiera fondos, destinados á la conservacion y fomento del culto público relijioso, quedan bajo la inmediata inspeccion y competencia de la autoridad eclesiástica [...]”. (Menéndez, 1855, Libro Séptimo, Título 3, p. 74) ${ }^{11}$ Sin embargo, el dinero y los bienes de la Iglesia continuaban siendo fuente de tensión y de disputas. En esa tensión de poderes se gestaba un proceso secularizador. Finalizaremos este 
artículo con el estudio del concor- dato entre El Salvador y la Santa Sede.

\section{Concordato y secularización}

Las independencias de ultramar tomaron desprevenida a la Santa Sede. Quien en realidad administraba la Iglesia en el nuevo continente era la Corona española. Así que de pronto se encontró con nuevas entidades políticas (estados, repúblicas, federaciones) que reclamaban como propio el patronato. En Centroamérica, un decreto federal del 11 de julio de 1831 consideró “inherente á la soberania nacional el derecho que, con el título de Patronato, se concede y se practica en los Estados Católicos". Declaró que mientras no existiera un concordato con la Santa Sede, "el Presidente de la República ejercerá el Patronato en los mismos términos que lo ejercian los reyes de España”. Extendió la facultad a los jefes de estado, "como Vice-Patronos, en todos los casos y negocios que no tengan conexion con los de otro Estado, ó que no toquen á las relaciones exteriores". (Menéndez,1855, Libro Séptimo, Título 1, p. 56) La profunda crisis de Centroamérica durante la Federación hizo imposible la firma de un concordato con la Santa Sede ${ }^{12}$.

El concordato definía y pactaba las funciones y las jurisdicciones de la Iglesia y del Estado. Ya en calidad de república independiente, El Salvador rubricó el concordato en abril de 1862. Delgado traza un relato amplio de las negociaciones entre la Santa Sede y el Estado salvadoreño (Delgado, 2011, pp. 479-487). En lo que resta de este apartado me interesa analizar el concordato como parte del proceso de secularización.

En el primer artículo, el concordato ratificó la identidad católica del Estado. Este debía garantizar a la Iglesia sus derechos y prerrogativas, "segun la ley de Dios y las disposiciones de los sagrados Cánones" (Arriola, 1868, p. 260). Este acuerdo fue un retroceso respecto de la protección del fuero interno del individuo. Además de declarar a la religión católica como "única verdadera, [que] profesa el Salvador, y [que] el Gobierno la protejerá con leyes sabias, justas y benéficas", la constitución de 1841 también decretó que "todo hombre es libre para adorar a Dios según su conciencia, sin que ningún poder ni autoridad pueda, con leyes, órdenes y mandatos, de cualquier naturaleza que sean, perturbar ó violentar las creencias privadas". En congruencia con el concordato, la constitución de 1864 simplificó el enunciado: "La Religion Católica, Apostólica y Romana, única verdadera, profesa $\mathrm{El}$ Salvador, y el Gobierno le dará toda 
protección" (Gallardo, 1945, pp. 115, 128).

El segundo punto esencial se pactó en torno a la enseñanza. El Estado no cedió a la Iglesia la administración y el control de la enseñanza, en sus diferentes ramas, pero sí hizo una sutil concesión que permitiría a las autoridades eclesiásticas intervenir en la educación, pública y particular: "la enseñanza en las Universidades, Colegios, Escuelas y demas Establecimientos de Instrucción, será conforme á la doctrina de la misma Religion Católica [...]". En virtud de ello, obispos y ordinarios velarían para que en la enseñanza de cualquier tipo nada se impartiera que fuera contrario a la religión y a la moral, y en caso de darse tal hecho "llamarán la atención del Gobierno para que ponga remedio á ello" (Arriola,1868, p. 260). Los clérigos podrían denunciar pero sería potestad del Estado corregir las faltas cometidas por los ciudadanos.

Sutil fue también la concesión en materia de censura. Los obispos ejercerían el derecho de censura "respecto de todos los libros ó publicaciones de cualquiera naturaleza, puestas en circulación, que tengan relacion al Dogma, á la disciplina de la Iglesia, y á la moral pública [...]”. El gobierno atendería las decisiones que los obispos tomaren "conforme á los sagrados Cánones, para defender la Religion, y evitar lo que pudiera serle contrario" (Arriola,1868, pp. 260-261). La censura quedó limitada. Cualquier publicación científica o técnica que no significara una amenaza para los dogmas podría circular sin problemas. En términos de secularización del saber y de la cultura era un logro importante (Monod, 2013, pp. 57-67). En el contexto de la romanización que estaba en curso (De Roux, 2014), el artículo siguiente aprobó la libre comunicación entre la Santa Sede y el obispado: "Siendo el Pontífice Romano el Gefe de la Iglesia universal por derecho divino, tanto los Obispos como el Clero y el pueblo, tendrán libre comunicacion con la Santa Sede Apostólica" (Arriola,1868, p. 261).

En un tema harto fundamental, como era el sostenimiento de la diócesis, el Estado se comprometió a proporcionar el dinero para la manutención del obispo, del cabildo catedralicio, del colegio seminario y para los gastos del culto y de fábrica de la iglesia catedral. (Arriola,1868), p. 268-269) ${ }^{13}$ En relación a los fondos para la manutención de los párrocos, el documento señaló que estos continuarían "percibiendo las primicias y los emolumentos dichos de estola, quedando al cuidado y conciencia del Ordinario el arreglo de los aranceles de éstos, hasta que el Gobierno les asigne una cóngrua segura é independiente, poniéndose de acuerdo para ello con el Obispo" (Arriola, 1868, pp. 261-262). 
En atención al sostén económico por parte del Estado, el Sumo Pontífice concedió al Presidente Gerardo Barrios, y a sus sucesores, el derecho de patronato, es decir, "el privilegio de presentar para cualesquiera vacantes de la Diócesi de San Salvador y de las demas que fueren erigidas en aquel territorio, á Eclesiásticos dignos é idóneos adornados de todas las cualidades requeridas por los sagrados Cánones". Los elegidos no debían asumir sus cargos antes de recibir las bulas de la Santa Sede. Sería obligación del presidente presentar el candidato a más tardar un año después de haberse verificado la vacante (Arriola, 1868, p. 262). Sobre las parroquias estipuló: “Todas las Parroquias serán provistas en concurso abierto, segun lo dispuesto por el Sagrado Concilio de Trento, debiendo los Ordinarios formar las ternas de los concurrentes aprobados, y dirijirlas al Presidente de la República, quien nombrará uno entre los propuestos [...]" (Arriola,1868, p. 263). La Santa Sede se reservó el derecho de crear nuevas diócesis y nuevas parroquias en el territorio, según las necesidades de los fieles, pero siempre obraría en acuerdo con el gobierno civil.

El concordato delimitó las áreas y las funciones que serían por entero de jurisdicción del gobierno eclesiástico: "Las causas relativas á la fé, á los Sacramentos, á las funciones sagradas, á las obligaciones y á los derechos anexos al Sagrado
Ministerio, y en general, todas las causas de naturaleza eclesiástica, pertenecen exclusivamente al juicio de la Autoridad Eclesiástica [...]" (Arriola,1868, p. 264). Por otro lado, la Santa Sede aprobó que se ventilaran en los tribunales laicos "las causas personales de los Eclesiásticos en materia civil, así como las causas concernientes á las propiedades y á otros derechos temporales de los Clérigos, de las Iglesias, de los Beneficios y de las demas fundaciones eclesiásticas". Aprobó que los tribunales laicos atendieran los delitos "estraños á la Religion" cometidos por el clero. En este punto añadió un conjunto de prerrogativas, como por ejemplo: "En el arresto y detencion de los Eclesiásticos se les guardarán los miramientos convenientes á su carácter, debiendo darse pronto aviso de dicho arresto al Obispo respectivo" (Arriola, 1868, pp. 264-265). Se acordó el respeto a las propiedades de la Iglesia y el derecho de los obispos a permitir el establecimiento de órdenes religiosas, previo acuerdo con el gobierno civil: "Los Obispos podrán establecer Ordenes ó Congregaciones de Regulares de ambos sexos en sus propias Diócesis, segun lo prescriben los sagrados Cánones; pero deberán ponerse previamente de acuerdo al intento, con el Gobierno" (Arriola, 1868, pp. 266-267).

Hemos destacado aquellos temas más relevantes y delicados en las complejas relaciones entre la Iglesia 
y el Estado. Después del fracaso de la Federación de Centroamérica (1823-1839) y después de obtenida la diócesis (1842), la República del Salvador por fin disponía de un concordato con la Santa Sede (1862). El concordato fue un logro de la Presidencia de Gerardo Barrios, cuyo gobierno no sobrevivió al levantamiento de los pueblos, la invasión de Rafael Carrera (presidente de Guatemala) y su alianza con Francisco Dueñas, quien sucediera a Barrios como presidente de $\mathrm{El}$
Salvador. Barrios sería fusilado posteriormente. El pacto con la Santa Sede no era garantía de unas relaciones cordiales entre ambos poderes, como quedó demostrado tiempo después, cuando surgió el reformismo laico y secularizante (1871-1890). Sin embargo, el análisis del concordato demuestra que su gestión y aprobación formó parte del proceso moderno de diferenciación (secularización) de las esferas política y religiosa.

\section{Conclusiones}

Lo secular o la secularización ha sido uno de los tópicos más estudiados por la academia moderna y contemporánea. En este trabajo asumimos la línea de investigación historiográfica propuesta por Roberto Di Stefano. Entendemos la secularización como un proceso de diferenciación funcional y de separación de esferas en el que el Estado y la Iglesia fueron protagonistas clave. La Iglesia Católica se revela como agente del proceso y como producto del mismo. En esa relación dialéctica se entiende que al mismo tiempo que la Iglesia va cobrando forma institucional - frente al Estado, que también está en proceso de formación-, es copartícipe del proceso de secularización; de forma que al consolidarse como institución es también producto de dicho proceso.
Las relaciones de colaboración, tensión y disputa entre el Obispo Tomás Miguel Pineda y Saldaña y algunas municipalidades demuestran que, en efecto, al mismo tiempo que pugnaba por cierta autonomía institucional y administrativa para la Diócesis de San Salvador, contribuía al proceso de secularización. En el manejo de ciertas cosas religiosas, como los fondos de fábrica, debían marcarse fronteras entre la municipalidad y la parroquia, entre el gobierno civil y el gobierno eclesiástico, entre el Estado y la Iglesia. Solo mediante ese esfuerzo de diferenciación (separación) la Iglesia salvadoreña podría salir fortalecida frente a un Estado salvadoreño, que también estaba en formación. La fe católica como credo nacional no estaba en discusión. La libertad de culto se debatiría en el último tercio del XIX, 
en el contexto de las reformas laicas y secularizantes.

Desde un plano más jurídico, el análisis del concordato (1862) entre el Estado salvadoreño y la Santa Sede demuestra que dicho pacto formó parte del proceso secularizador. Los acuerdos tomados por ambas partes evidencian diferenciación y separación de funciones, acciones y responsabilidades. Ciertamente, el Estado se definía como esencialmente católico. Pero el concordato marcaba pautas que deslindaban las acciones de cada uno. Desde la perspectiva eclesial, fortalecía a la Diócesis de San Salvador; desde la perspectiva estatal, facilitaba el control y la vigilancia de la Iglesia por parte del Estado.

Con todo, este trabajo es solo una introducción y una primera aproximación al proceso de secularización del siglo diecinueve salvadoreño, según los términos como hemos definido dicho proceso. Harán falta nuevos trabajos, con nuevos problemas de investigación y nuevas fuentes documentales, a fin de ampliar, discutir, problematizar o refutar la perspectiva aquí planteada. A fin de cuentas, la secularización es uno de los conceptos más polisémicos y controversiales.

\section{Referencias bibliográficas}

- Acosta, A. (2014). Los orígenes de la burguesía de El Salvador. El control sobre el café y el Estado 1848-1890. San Salvador: UFG Editores.

- Acosta, A. (2016). "Desigualdades sociales y fiscales en El Salvador a mediados del siglo XIX. Una aproximación”. En: Vidales, R. y Arias, D. (eds). Historia de las desigualdades sociales en América Central. Una visión interdisciplinaria, siglos XVIII-XXI. San José: Centro de Investigaciones Históricas de América Central, págs. 24-49.

- Acosta, A. y Flores, M. (2011). "Municipio y Estado: la política municipal de los gobiernos de El Salvador hacia 1900”. En: López, C. (comp). Poder, actores sociales y conflictividad. El Salvador, 1786-1972. San Salvador: Dirección Nacional de Investigaciones en Cultura y Arte, págs. 169-208.

- Arriola, D. J. de (1868). Nociones de derecho jurisdiccional, civil y criminal, segun los principios y reglas del derecho internacional. Estractadas de los mejores autores, por el coronel doctor Don Doroteo Jose de Arriola, fiscal general de hacienda de la república, y catedrático de practica forense y de derecho administrativo en la Universidad del Salvador; para el uso de los cursantes de aquellas asignaturas. San Salvador: Imprenta del Gobierno. 
- Avendaño, X. (2011). "Reformas en Centroamérica a finales de la dominación española: la Intendencia de San Salvador”. En: López, Carlos (comp). Poder, actores sociales y conflictividad. El Salvador, 1786-1972. San Salvador: Dirección Nacional de Investigaciones en Cultura y Arte, págs.17-57.

- Avendaño, X. (2018). El trienio constitucional. Moderación, innovación y autonomía en el Reino de Guatemala, 1820-1823. San Salvador: UCA Editores.

- Ayala, L. (2011). La iglesia y la independencia política centroamericana: el caso del Estado de El Salvador (1808-1832). San Salvador: Universidad Don Bosco.

- Barón, R. (2002). La población de El Salvador. San Salvador: Dirección de Publicaciones e Impresos.

- Blancarte, R. (2008). "Laicidad y laicismo en América Latina”. Estudios Sociológicos, México, D.F., 76, págs. 139-164.

- Bolaños, R. (2000). Ilmo. Mons. Dr. Don Jorge de Viteri y Ungo. Primer Obispo de San Salvador. s/d.

- Cardenal, R. (2001). El poder eclesiástico en El Salvador 1871-1931. San Salvador: Dirección de Publicaciones e Impresos.

- Casanova,J.(2012).Genealogías de la secularización. Barcelona:Universidad Nacional Autónoma de México, Facultad de Ciencias Políticas y Sociales, Anthropos.

- Castellón, J. (2014). Fiestas, vida y comida en el interior del Reino de Guatemala. San Salvador y Sonsonate, siglo XVIII. San Salvador: Universidad Don Bosco.

- Constitución política de la Monarquía española (2009). Cádiz: Quorum Editores.

- Cortés, J. (2014). "Las discusiones sobre el patronato en Colombia en el siglo XIX”. Historia Crítica, Bogotá, 52, págs. 99-122.

- Delgado, J. (2011). Historia de la Iglesia en El Salvador. San Salvador: Dirección de Publicaciones e Impresos.

- De Roux, R. (2014). "La romanización de la Iglesia católica en América Latina: una estrategia de larga duración”. Pro-Posições, Campinas, 1 (73), págs. 31-54.

- Del Valle, G. (2014). "Las funciones crediticias de las cofradías y los negocios de los mercaderes del Consulado de la ciudad de México, fines 
del siglo XVIII y principios del XIX". Revista de Indias, Madrid, 261, págs. 507-538.

- Di Stefano, R. (2002). "Orígenes del movimiento asociativo: de las cofradías coloniales al auge mutualista”. En: Luna, Elba y Cecconi, Elida (coord). De las cofradías a las organizaciones de la sociedad civil. Historia de la iniciativa asociativa en Argentina 1776-1990. Argentina: Gadis /Grupo de Análisis y Desarrollo Institucional y Social, págs. 23-97.

- Di Stefano, R. (2004). El púlpito y la plaza. Clero, sociedad y política de la monarquía católica a la república rosista. Buenos Aires: Siglo XXI.

- Di Stefano, R. (2011).“Por una historia de la secularización y de la laicidad en la Argentina”. Quinto Sol, Buenos Aires, 1, págs. 1-30.

- Di Stefano, R. (2012). “¿De qué hablamos cuando decimos "Iglesia”? Reflexiones sobre el uso historiográfico de un término polisémico". Ariadna histórica. Lenguajes, conceptos, metáforas, Universidad del País Vasco, 1, págs. 197-222.

- Diccionario de Derecho Canónico. Tomo III. (1848). Madrid: Imprenta de D. José C. De la Peña.

- Gallardo, M. Á. (Comp.) (1945). Cuatro constituciones federales de Centro América y las constituciones políticas de El Salvador. San Salvador: Tipografía La Unión. Colecciones Especiales de la Biblioteca “P. Florentino Idoate, S.J."

- González, J. (2012). Del "ciudadano católico" al "ciudadano laico". La escuela pública primaria y la formación de los futuros ciudadanos. El Salvador 1824-1890. Tesis de Doctorado en Filosofía Iberoamericana. Universidad Centroamericana José Simeón Cañas. San Salvador.

- Gudmundson, L. y Lindo-Fuentes, H. (1995). Central America, 1821-1871. Liberalism before Liberal Reform. Tuscaloosa: The University of Alabama Press.

- Guerrero,A. (2016). “El crédito a partir de los recursos de las cofradías en la provincia de Pamplona, siglo XVIII". Anuario de Historia Regional y de las Fronteras XXI, Bucaramanga, 2, págs. 219-248.

- Herrera,S.(2003).“La idea borbónica de buen gobierno en las poblaciones: La Intendencia de San Salvador (1786-1808)". En: Gómez, A. y Herrera, S. (comps). Mestizaje, poder y sociedad. Ensayos de historia colonial de las Provincias de San Salvador y Sonsonate. San Salvador: FLACSO, págs. 97-131. 
- Herrera, S. (2004). "La educación de primeras letras en el San Salvador y Sonsonate borbónicos, 1750-1808”. Estudios Centroamericanos, 671, págs. 927-947.

- Herrera, S. (2005). La herencia gaditana. Bases tardío-coloniales de las municipalidades salvadoreñas. 1808-1823 (Tesis de Doctorado en Historia de América). Universidad Pablo de Olavide, Sevilla.

- Herrera, S. (2013). El ejercicio de gobernar. Del cabildo borbónico al ayuntamiento liberal: El Salvador colonial, 1750-1821. Castelló de la Plana: Publicacions de la Universitat Jaume I.

- Herrera, S. (2018). "Independencia, jurisdicciones y legitimidad política: los ayuntamientos frente al gobierno de San Salvador, 1821-1823". En: Chaves, A. y Payne, E. (comps.). Reflexiones en torno al Bicentenario de las Independencias Centroamericanas. Independencias y formación de los Estados Nacionales, 1821-1860. Alajuela: Museo Histórico Cultural Juan Santamaría, págs. 73-96.

- Laboa, J., Pierini, F. y Zagueni, G. (2005). Historia de la Iglesia. Edad Antigua, Media, Moderna y Contemporánea, y La Iglesia en España. Madrid: San Pablo.

- Lavrin,A.(1998).“Cofradías novohispanas: economías material y espiritual”. En: Martínez, M. del P., von Wobeser, G. y Múñoz, J. (coord). Cofradías, Capellanías y obras pías en la América Colonial. México, D.F.: Universidad Nacional Autónoma de México, Instituto de Investigaciones Históricas, Facultad de Filosofía y Letras, págs. 49-64.

- Libro de visitas pastorales (1850-1854). Archivo Histórico del Arzobispado de San Salvador.

- Libro de visitas pastorales. T. 2 (1857-1867). Archivo Histórico del Arzobispado de San Salvador.

- Lionetti, L. (2007). La misión política de la escuela pública: Formar a los ciudadanos de la república, (1870-1916). Buenos Aires: Miño y Dávila.

- López, C. (2006). “Las municipalidades y la educación: las escuelas de primeras letras a mediados del siglo XIX". Cultura. Revista del Consejo Nacional para la Cultura y el Arte, San Salvador, 93, págs. 12-33.

- López, C. (2007). Poder central y poder local en la construcción del Estado en El Salvador, 1840-1890 (Tesis de Doctorado en Historia). Universidad de Costa Rica. San José.

- López, C. (2018). Municipalidades, gobernaciones y presidencia en la construcción del Estado en El Salvador, 1840-1890. San Salvador: Universidad de El Salvador, Universidad Autónoma Metropolitana. 
- López, R. (1999). Mitras salvadoreñas. San Salvador: Banco de Construcción y Ahorro.

- Malaina, S. (1944). Historia de la erección de la Diócesis de San Salvador escrita con motivo de su primer centenario. San Salvador, s.d.

- Menéndez, I. (Comp.) (1855). Recopilación de las leyes Del Salvador, en Centro-América, Guatemala: Imprenta de L. Luna. Colecciones Especiales de la Biblioteca "P. Florentino Idoate, S.J."

- Monod, J.-C. (2013). Qué es la laicidad. Barcelona: Proteus.

- Pérez, C. (2012). “La configuración del espacio económico en el marco de la construcción del Estado: el Oriente salvadoreño, 1840-1855". Revista Complutense de Historia de América, Madrid, 38, págs. 129-151.

- Pérez, C. (2018). San Miguel y el oriente salvadoreño. La construcción del Estado de El Salvador, 1780-1865. San Salvador: UCA Editores.

- Pinto, J. C. (1986). Centroamérica, de la colonia al Estado nacional (18001840). Guatemala: Editorial Universitaria de Guatemala.

- Poulat, É. (2012). Nuestra laicidad pública. México, D.F.: Fondo de Cultura Económica.

- Rausch, J. M. (1993). La educación durante el federalismo. La reforma escolar de 1870. Santafé de Bogotá: Instituto Caro y Cuervo y Universidad Pedagógica Nacional.

- Tanck de Estrada, D. (2004). "Los bienes y la organización de las cofradías en los pueblos de indios del México colonial. Debate entre el Estado y la Iglesia”. En: Martínez, P., Speckman, E. y von Wobeser, G. (coords). La Iglesia y sus bienes. De la amortización a la nacionalización. México, D.F.: Universidad Autónoma de México, Instituto de Investigaciones Históricas, págs. 33-57.

- Valdés, R. (2010). Masones, liberales y ultramontanos salvadoreños: debate político y constitucional en algunas publicaciones impresas, durante la etapa final del proceso de secularización del estado salvadoreño (1885-1886) (Tesis de Doctorado en Filosofía Iberoamericana). Universidad Centroamericana José Simeón Cañas. San Salvador.

- Vásquez, O. (2012). El debate sobre la educación femenina en el contexto de la laicización del Estado salvadoreño (1871-1889) (Tesis de Doctorado en Filosofía Iberoamericana). Universidad Centroamericana José Simeón Cañas. San Salvador. 
- Vázquez, M. (2009). El Imperio Mexicano y el Reino de Guatemala. Proyecto político y campaña militar, 1821-1823. México, D.F.: Universidad Nacional Autónoma de México y Fondo de Cultura Económica.

- Vilanova, S. (1911). Apuntamientos de historia patria eclesiástica. San Salvador: Imprenta Diario Del Salvador.

- Webre, S. (1993)."Poder e ideología: la consolidación del sistema colonial (1542-1700)”. En: Pinto, J., (ed). Historia general de Centroamérica II: el régimen colonial. Madrid: Sociedad Estatal Quinto Centenario, Facultad Latinoamericana de Ciencias Sociales, págs. 151-218.

- Wortman, M. (2012). Gobierno y sociedad en Centroamérica 1680-1840. Guatemala: Cara Parens.

\section{Notas}

1. Cursivas del autor en ambas citas.

2. En virtud del patronato los monarcas españoles disponían en sus dominios de las "jurisdicciones territoriales de la Iglesia, presentaban candidatos a todos los oficios eclesiásticos y cobraban el diezmo, reteniendo parte de él y haciendo distribución del resto. También reclamaban el derecho de aprobar la publicación de los edictos papales" (Webre, 1993, p. 170).

3. Los firmantes del decreto fueron Manuel José Arce, Juan Manuel Rodríguez, Juan de Dios Mayorga, Antonio José Cañas, Domingo Antonio Lara y Ramón Meléndez, secretario (Malaina, 1944, p. 54).

4. Guatemala no tenía arzobispo desde 1829, por la expatriación del Arzobispo Casaus y Torres, Comayagua estaba sin obispo desde 1820, León no tenía desde 1825. Costa Rica y El Salvador gestionaban la erección de sus propias diócesis. Viteri y Ungo fue comisionado por El Salvador, Costa Rica, Honduras y Guatemala para que gestionara la erección de las nuevas diócesis, con sus respectivos obispos, y el nombramiento de nuevos prelados para las sedes vacantes (Bolaños, 2001, pp. 65-101).
5. Cursiva del autor.

6. Cursiva del autor.

7. Cursiva del autor.

8. Cursiva del autor.

9. Cursiva del autor.

10. El tajo fue un impuesto municipal aprobado en 1841. Según el artículo primero: "Los dueños de las reses, que se maten para el consumo, en los pueblos ó valles del Estado, pagarán por todo derecho de alcabala, seis reales por cada cabeza, de cuyo producido se formará un fondo en cada partido para proteger la enseñanza de primeras letras". (Menéndez, 1855, Libro Octavo, Título 2, p. 124). Durante buena parte del XIX la educación primaria se conoció como "escuela de primeras letras". Los ingresos del tajo no siempre se invirtieron en las escuelas (González, 2012: 85; López, 2006: 12-33).

11. Según la investigación de Delgado, desde 1827 los fondos de fábrica habían sido administrados por las municipalidades (2011: 463).

12. La República del Centro de América quedó conformada por cinco estados: El Salvador, Guatemala, Honduras, Nicaragua y Costa Rica. 
13. En total el Estado entregaría anualmente quince mil pesos, repartidos así: (1) Colegio Seminario: cuatro mil doscientos; (2) Obispo diocesano: cuatro mil doscientos; (3) Cabildo Eclesiástico: cinco mil cien; (4) Fábrica de la Catedral de San Salvador: mil quinientos. (Arriola, 1868, pp. 268-269). 
